\title{
CRESCIMENTO DE ORQUÍDEAS EPÍFITAS IN VITRO: ADIÇÃO DE POLPA DE FRUTOS( $\left(^{1}\right)$
}

\author{
GIULIO CESARE STANCATO $\left(2^{*}\right)$; MÔNICA FERREIRA ABREU $\left({ }^{3}\right)$; \\ ÂNGELA MARIA CANGIANI FURLANI $\left({ }^{3}\right)$
}

\begin{abstract}
RESUMO
Este trabalho foi desenvolvido com o objetivo de estudar o efeito das polpas de frutas no crescimento de plântulas de orquídeas in vitro. Três espécies de orquídeas epífitas brasileiras foram usadas: Laelia longipes Rchb.f., Laelia tenebrosa Rolfe e Miltonia spectabilis (Lindley). Os seguintes meios nutritivos foram testados: 10:10:10 (N:P:K), na concentração de $1 \mathrm{~g} \mathrm{~L}^{-1}, 10: 30: 20,1 \mathrm{~g} \mathrm{~L}^{-1}$, polpa de maçã, 10,0 $\mathrm{g} \mathrm{L}^{-1}$, polpa de tomate, $10 \mathrm{~g} \mathrm{~L}^{-1}$, polpa de banana, $50 \mathrm{~g} \mathrm{~L}^{-1}$, e também os meios de Knudson, Vacin e Went, Murashige e Skoog. Nas plântulas de L. longipes, cultivadas em 10:10:10 e polpa de banana observou-se o maior acúmulo de, massa e naquelas cultivadas em MS o menor. Pela análise dos resultados para Miltonia spectabilis observou-se que os meios 10:30:20 e polpa de banana proporcionaram o maior acúmulo de massa seca e no meio MS, o menor acúmulo. Em ordem decrescente de acúmulo de matéria seca total estão os meios 10:30:20 e polpa de banana, seguidos por 10:10:10, polpa de tomate, KNUDSON (58,3\%), VACIN e Went (18,7\%), polpa de maçã $(13,2 \%)$ e MS (4,1\%). Para Laelia tenebrosa, as plântulas cultivadas no meio polpa de banana incorporaram o maior conteúdo de matéria seca, seguidas pelas plântulas cultivadas em meio com 10:10:10. Os outros meios propiciaram acúmulo reduzido.
\end{abstract}

Palavras-chave: meios nutritivos; micropropagação; nutrição in vitro.

\section{ABSTRACT \\ THE PULPS OF FRUITS IN THE GROWTH OF EPIPHYTIC ORCHIDS}

This work was carried out with the aim of studying the effect of pulp of fruits on the growth of orchids seedlings in vitro. Three species of epiphytic brazilian orchids were used: Laelia longipes Rchb.f., Laelia tenebrosa Rolfe e Miltonia spectabilis (Lindley). The following nutritive media were tested: 10:10:10 $(\mathrm{N}: \mathrm{P}: \mathrm{K})$, at $1 \mathrm{gL}^{-1}, 10: 30: 20$ at $1 \mathrm{gL}^{-1}$, apple pulp, at $10 \mathrm{gL}^{-1}$, tomato pulp at $10 \mathrm{gL}^{-1}$, banana pulp at $50 \mathrm{gL}^{-1}$, and also the KNUDSON, VAcin and Went, Murashige and SKOOG (MS) media. In seedlings of L. Longipes cultivated in 10:10:10 and banana pulp was observed higher accumulation, and the lowest one in MS. Analysis of dry mass results for Miltonia spectabilis showed that the media 10:30:20 and banana pulp propiciated the highest dry mass accumulation and the MS medium, the lowest. In decreasing order of total dry mass accumulation are the media 10:30:20 and banana pulp, followed by 10:10:10, tomato pulp, KNUDSON (58,3\%), VACIN e Went $(18,7 \%)$, apple pulp (13,2\%) and MS (4,1\%). For Laelia tenebrosa, seedlings cultivated in banana pulp incorporated higher dry mass content, followed by those cultivated in 10:10:10, whereas the remaining media propitiated reduced accumulation.

Key words: orchids micropropagation; nutritive media; in vitro nutrition.

$\left({ }^{1}\right)$ Recebido para publicação em 31 de maio de 2006 e aceito em 20 de agosto de 2007.

$\left({ }^{2}\right)$ Instituto Agronômico, Centro de Horticultura, Caixa Postal 28, 13012-970 Campinas (SP). E-mail: stancato@iac.sp.gov.br. $\left(^{*}\right)$ Autor correspondente.

$\left({ }^{3}\right)$ Centro de Solos e Recursos Agroambientais, Instituto Agronômico, Campinas (SP). 


\section{INTRODUÇÃO}

Os meios nutritivos empregados na cultura de tecidos vegetais foram estabelecidos a partir das exigências das plantas inteiras, com modificações para atender às necessidades específicas in vitro (CALDAS et al., 1998). Assim, vários compostos são adicionados para suprir as necessidades metabólicas, energéticas e estruturais da célula, uma vez que as mesmas vias bioquímicas básicas que operam nas plantas são mantidas nos tecidos cultivados in vitro. A maioria dos meios nutritivos é composta por macro e micronutrientes minerais, vitaminas, açúcares, reguladores vegetais e suplementos orgânicos (Gamborg, 1984; Knudson, 1946; Murashige e Skoog, 1962; Vacin e Went, 1949; White, 1951); o emprego dessas substâncias permite a reprodutibilidade dos meios, tendo em vista que as constituições químicas são conhecidas e suas concentrações podem ser previamente determinadas.

Porém, no cultivo de orquídeas in vitro existem vários relatos da utilização de polpas de frutas na formulação de meios nutritivos, incluindo a água de coco (ARditti, 1992; Vacin e Went, 1949) e a polpa de banana (WithNER, 1974). Neste contexto, o emprego desses compostos proporciona melhora no desenvolvimento de plântulas, permitindo maior vigor e crescimento durante essa fase (Reinert e MoHr, 1967). O que se sabe sobre esses compostos é que são ricos em fibras, ácidos graxos, compostos nitrogenados, sais minerais, vitaminas, ácidos orgânicos, açúcares, reguladores vegetais e demais substâncias (WATt e Merrill, 1963). Em decorrência, a sua ação é de difícil previsão já que muitos fatores estariam envolvidos na sua determinação.

O objetivo deste trabalho foi verificar o efeito da adição das polpas de frutas no crescimento de plântulas de orquídeas in vitro, durante a fase de micropropagação.

\section{MATERIAL E MÉTODOS}

Para a realização deste trabalho foram empregadas três espécies de orquídeas epífitas brasileiras: Laelia longipes Rchb.f., Laelia tenebrosa Rolfe e Miltonia spectabilis (Lindley). No início, as plântulas estavam com 3-4 folhas e massa seca média de 0,82, 0,37 e $1,09 \mathrm{mg}$ respectivamente. A fase experimental teve a duração de um ano, sendo as plântulas cultivadas em frascos de vidro, com quatro repicagens sucessivas de três meses de duração cada uma. À medida que as plântulas foram crescendo, a densidade no frasco foi variando de $30,15,10$ e 5 plântulas. Durante o período de incubação, em sala de cultivo, os frascos foram mantidos em prateleiras de aço sob condições parcialmente controladas de temperatura $\left(21-24^{\circ} \mathrm{C}\right)$ e luz fotossinteticamente ativa (40 ì. $\left.\mathrm{m}^{-2} \cdot \mathrm{s}^{-1}\right)$, sendo o fotoperíodo de 16 horas.

Foram testados os meios nutritivos 10:10:10 (N:P:K), na concentração de $1 \mathrm{gL}^{-1} ; 10: 30: 20,1 \mathrm{gL}^{-1}$; polpa de maçã, $10 \mathrm{gL}^{-1}$; polpa de tomate, $10 \mathrm{gL}^{-1}$; polpa de banana, $50 \mathrm{gL}^{-1}$; e também os meios de acordo com os trabalhos de KNUDSON (1946), VACIN e WENT (1949) e Murashige e SKoog (1962), cuja composição mineral inicial foi determinada por ICP-OES para cada nutriente e estão apresentadas na tabela 1. Em todos os meios foram acrescidos $2 \%$ de sacarose, $0,9 \%$ de ágar, e o $\mathrm{pH}$ corrigido para 5,8. Os frascos contendo $50 \mathrm{~mL}$ dos meios nutritivos foram esterilizados por autoclavagem a $121^{\circ} \mathrm{C}(104 \mathrm{kPa})$ durante 20 minutos.

Para cada orquídea estudada, o delineamento experimental utilizado foi o inteiramente casualizado com oito tratamentos, cinco repetições e amostragens no início e no fim do experimento; foram considerados cada meio nutritivo um tratamento e cada plântula uma repetição. Os testes de significância empregados foram os testes $\mathrm{F}$ e o de Tukey a 5\%, sendo avaliados em plântulas os seguintes parâmetros: matéria seca total, matéria seca da parte aérea, matéria seca das raízes e relação parte aérea/raízes (PA / raízes). Nos meios de cultura, foram analisados os teores de macro e micronutrientes minerais em alíquotas retiradas no início e no fim do experimento.

\section{RESULTADOS E DISCUSSÃO}

\section{Laelia longipes}

Os valores da matéria seca acumulada e a relação PA / raízes, em plântulas de L. longipes, são apresentados nas tabelas 2 e 3 . Em relação à matéria seca total, as plântulas cultivadas nos meios 10:10:10 e com polpa de banana obtiveram maior acúmulo e as cultivadas no meio MS tiveram o menor, correspondendo a $24,2 \%$ do meio $10: 10: 10$ e $25,8 \%$ do meio com polpa de banana. Nos demais meios de cultura, as plântulas tiveram valores intermediários. Além disso, considerando o acúmulo de matéria seca na parte aérea, na análise dos resultados, observa-se que as plântulas cultivadas em meio com polpa de banana tiveram o maior acúmulo, e as plântulas cultivadas em meio com polpa de maçã obtiveram o menor, correspondendo a $6,5 \%$ das primeiras.

Em relação às raízes, o maior acúmulo de matéria seca foi verificado em plântulas cultivadas no meio 10:10:10, cujos valores alcançados, quando comparados aos obtidos pelas plântulas cultivadas 
nos demais meios nutritivos, são bem superiores, representando cerca de $215 \%$ a mais do que o segundo maior acúmulo, no meio 10:30:20, e em torno de $1.000 \%$ em relação ao menor acúmulo de matéria seca nas raízes, ou seja, plântulas cultivadas em meio MS. Nos demais tratamentos, em ordem decrescente, as plântulas obtiveram valores intermediários, a saber: polpa de tomate, KNUDSON, polpa de maçã, polpa de banana e VACIN e WeNT.

Quanto à relação $\mathrm{PA} /$ raízes, indicativo do particionamento da matéria seca entre os órgãos, a análise dos resultados mostra que nas plântulas cultivadas nos meios 10:10:10, polpa de maçã e KNUDSON, os valores foram menores do que um, ou seja, houve maior acúmulo de matéria seca nas raízes. Ao contrário, um incremento na matéria seca da parte aérea foi observado nas plântulas cultivadas nos meios com polpa de banana, MS, polpa de tomate, 10:30:20 e VACIN e WENT.

\section{Miltonia spectabilis}

Na tabela 4, são apresentados os valores da matéria seca acumulada em plântulas de M. spectabilis, bem como os valores da relação PA/raízes. Verifica-se que o maior acúmulo de matéria seca da parte aérea ocorreu em plântulas cultivadas em meio nutritivo contendo polpa de banana, seguido pelos tratamentos polpa de tomate, 10:30:20, 10:10:10, KNUDSON, VACIN e WENT, polpa de maçã e MS, que correspondem a 83,7\%; $77,1 \% ; \quad 66,4 \%$; 59,3\%； 22,8\%； $10,6 \% ; 4,8 \%$, comparativamente ao primeiro. Com relação à matéria seca das raízes, plântulas cultivadas em meio nutritivo com 10:30:20 foram as que mais acumularam; os demais tratamentos, ou seja, 10:10:10, polpa de banana, KNUDSON, polpa de tomate, polpa de maçã, VACIN e WENT e MS, resultaram em valores percentuais comparativos ao primeiro tratamento em: $93,4 \% ; 78,4 \% ; 46,1 \% ; 27,5 \%$; $12,6 \%, 11,9 \%, 2,7 \%$ respectivamente (Tabela 5).

Tabela 1. Concentração inicial em $\mathrm{mg} \mathrm{L}^{-1}$ dos meios nutritivos empregados no crescimento de plântulas de Laelia longipes, Miltonia spectabilis e Laelia tenebrosa (Orchidaceae), em quatro repicagens sucessivas de três meses cada uma. $(\mathrm{n}=5)$

\begin{tabular}{|c|c|c|c|c|c|c|c|c|}
\hline \multirow{2}{*}{ Análises } & \multirow{2}{*}{ 10:10:10 } & \multirow{2}{*}{ 10:30:20 } & \multicolumn{3}{|c|}{ Polpa } & \multirow{2}{*}{ Knudson } & \multirow{2}{*}{ V e W } & \multirow{2}{*}{ MS } \\
\hline & & & Maçã & Tomate & $\overline{\text { Banana }}$ & & & \\
\hline$P$ & 59,0 & 186,4 & 0,52 & 9,25 & 9,04 & 61,48 & 72,55 & 364,0 \\
\hline K & 48,0 & 147,7 & 71,4 & 142,9 & 265,4 & 159,4 & 632,8 & 525,6 \\
\hline $\mathrm{Ca}$ & 37,68 & 12,28 & 24,2 & 19,59 & 30,2 & 51,67 & 63,12 & 90,63 \\
\hline $\mathrm{Mg}$ & 30,02 & 12,26 & 8,59 & 7,53 & 14,26 & 18,05 & 36,71 & 27,27 \\
\hline$S$ & 167,77 & 66,27 & 55,34 & 52,26 & 56,48 & 396,72 & 385,39 & 111,43 \\
\hline $\mathrm{Fe}$ & 0,4 & 0,65 & 0,7 & 0,72 & 0,71 & 0,9 & 2,74 & 5,35 \\
\hline $\mathrm{Mn}$ & 0,83 & 0,15 & 0,98 & 0,91 & 2,53 & 2,61 & 5,71 & 0,1 \\
\hline $\mathrm{Zn}$ & 0,2 & 0,32 & 0,18 & 0 & 0,3 & 0,4 & 0,3 & 1,2 \\
\hline $\mathrm{Na}$ & 74,9 & 103,0 & 98,3 & 145,2 & 121,8 & 215,4 & 173,3 & 173,4 \\
\hline
\end{tabular}

Tabela 2. Acúmulo de matéria seca e relação alométrica após quatro cultivos sucessivos de três meses, em plântulas de um ano de Laelia longipes (Orchidaceae), quando crescidas em diferentes meios nutritivos, in vitro. Os valores de matéria seca são dados para a parte aérea (P.A.), raízes e total ( $\mathrm{n}=5$

\begin{tabular}{lcccc}
\hline \multirow{2}{*}{ Tratamentos } & \multicolumn{3}{c}{ Matéria seca $\left(^{1}\right)$} & Total $\left(^{2}\right)$ \\
\cline { 2 - 4 } & P.A. $\left(^{2}\right)$ & Raízes $\left(^{2}\right)$ & P.A./Raízes \\
\cline { 2 - 4 } 10:10:10 (N:P:K) & $10,71 \mathrm{c}$ & $31,61 \mathrm{a}$ & $42,32 \mathrm{a}$ & 0,34 \\
10:30:20 (N:P:K) & $23,60 \mathrm{~b}$ & $14,66 \mathrm{~b}$ & $38,26 \mathrm{~b}$ & 1,61 \\
Polpa de maçã & $2,05 \mathrm{f}$ & $10,07 \mathrm{e}$ & $12,12 \mathrm{e}$ & 0,20 \\
Polpa de tomate & $23,54 \mathrm{~b}$ & $12,68 \mathrm{c}$ & $36,22 \mathrm{~b}$ & 1,86 \\
Polpa de banana & $31,39 \mathrm{a}$ & $9,16 \mathrm{ef}$ & $40,55 \mathrm{a}$ & 3,43 \\
Knudson & $9,48 \mathrm{~d}$ & $11,38 \mathrm{~d}$ & $20,86 \mathrm{c}$ & 0,83 \\
V \& W & $10,32 \mathrm{~cd}$ & $8,49 \mathrm{f}$ & $18,81 \mathrm{~d}$ & 1,21 \\
MS & $7,20 \mathrm{e}$ & $3,05 \mathrm{~g}$ & $10,25 \mathrm{f}$ & 2,36 \\
\hline
\end{tabular}

$\left({ }^{1}\right)$ Teste F (P.A.)= 1588,86; teste F (Raízes)= 941,78; teste $\mathrm{F}$ (Total)= 1318,86. Análise de variância com valores transformados $(\sqrt{ } \mathrm{x})$.

$\left({ }^{2}\right)$ Letras iguais na coluna não diferem estatisticamente pelo teste de Tukey a $5 \%$. 
Tabela 3. Composição mineral e análise química $\left(\mathrm{mg} \cdot \mathrm{L}^{-1}\right)$ dos meios nutritivos empregados no crescimento de plântulas de Laelia longipes (Orchidaceae), após um ano de cultivo in vitro, em quatro repicagens sucessivas de três meses cada uma. $(\mathrm{n}=5)$

\begin{tabular}{|c|c|c|c|c|c|c|c|c|}
\hline \multirow{2}{*}{ Análises } & \multirow{2}{*}{ 10:10:10 } & \multirow{2}{*}{$10: 30: 20$} & \multicolumn{3}{|c|}{ Polpa } & \multirow{2}{*}{ Knudson } & \multirow{2}{*}{$\mathrm{V}$ e $\mathrm{W}$} & \multirow{2}{*}{ MS } \\
\hline & & & Maçã & Tomate & Banana & & & \\
\hline $\mathrm{P}$ & 4,0 & 15,0 & $<0,1^{*}$ & 5,0 & $<0,1$ & 11,0 & 3,0 & $<0,1$ \\
\hline K & 5,0 & 13,0 & 2,0 & 7,4 & 10,0 & 16,0 & 27,0 & 32,0 \\
\hline $\mathrm{Ca}$ & 3,0 & 4,0 & 3,0 & 4,0 & 3,0 & 17,0 & 5,0 & 7,0 \\
\hline $\mathrm{Mg}$ & 0,5 & 0,5 & 0,5 & 1,0 & 0,5 & 5,0 & 1,5 & 1,5 \\
\hline S & 2,0 & 2,0 & 2,0 & 4,0 & 5,0 & 56,0 & 23,0 & 12 \\
\hline $\mathrm{Fe}$ & 0,2 & 0,3 & 0,5 & 0,6 & 0,4 & 0,8 & 0,5 & 0,7 \\
\hline $\mathrm{Mn}$ & $<0,1$ & $<0,1$ & $<0,1$ & $<0,1$ & $<0,1$ & 0,3 & 1,0 & $<0,1$ \\
\hline $\mathrm{Zn}$ & 0,1 & 0,2 & 0,1 & 0,2 & 0,1 & 0,3 & 0,2 & 0,2 \\
\hline $\mathrm{Na}$ & 2,0 & 2,0 & 2,0 & 3,0 & 2,0 & 5,0 & 4,0 & 4,0 \\
\hline $\mathrm{pH}$ & 4,2 & 4,2 & 5,2 & 5,8 & 5,0 & 3,9 & 4,8 & 4,5 \\
\hline $\mathrm{CE}$ & 72 & 160 & 34 & 280 & 52 & 360 & 190 & 288 \\
\hline
\end{tabular}

*Valores abaixo do limite de detecção.

Tabela 4. Acúmulo de matéria seca e relação alométrica após quatro cultivos sucessivos de três meses, em plântulas de um ano de Miltônia spectabilis (Orchidaceae), quando crescidas em diferentes meios nutritivos, in vitro. Os valores de matéria seca são dados para a parte aérea (P.A.), raízes e total $(n=5)$

\begin{tabular}{|c|c|c|c|c|}
\hline \multirow{2}{*}{ Tratamentos } & \multicolumn{3}{|c|}{ Matéria Seca $\left({ }^{1}\right)$} & \multirow{2}{*}{ P.A./Raízes } \\
\hline & P.A. $\left({ }^{2}\right)$ & Raízes $\left({ }^{2}\right)$ & Total $\left({ }^{2}\right)$ & \\
\hline \multicolumn{5}{|c|}{$\longrightarrow \mathrm{mg} /$ plântula $\longrightarrow$} \\
\hline 10:10:10 (N:P:K) & $24,42 \mathrm{~d}$ & $43,61 b$ & $68,03 b$ & 0,56 \\
\hline 10:30:20 (N:P:K) & $28,37 \mathrm{c}$ & $46,69 a$ & $75,06 a$ & 0,61 \\
\hline Polpa de maçã & $3,92 \mathrm{~g}$ & $5,88 \mathrm{f}$ & $9,80 \mathrm{e}$ & 0,67 \\
\hline Polpa de tomate & $30,77 \mathrm{~b}$ & $12,85 \mathrm{e}$ & $43,62 c$ & 2,39 \\
\hline Polpa de banana & $36,79^{\mathrm{a}}$ & $36,62 c$ & $73,41 a$ & 1,01 \\
\hline Knudson & $21,81 \mathrm{e}$ & $21,51 \mathrm{~d}$ & $43,32 \mathrm{c}$ & 1,01 \\
\hline $\mathrm{V} \& \mathrm{~W}$ & $8,34 \mathrm{f}$ & $5,56 \mathrm{f}$ & $13,92 d$ & 1,50 \\
\hline MS & $1,76 \mathrm{~h}$ & $1,26 \mathrm{~g}$ & $3,02 f$ & 1,40 \\
\hline
\end{tabular}

$\left({ }^{1}\right)$ Teste $F($ P.A. $)=2542,66$; teste $F($ Raízes $)=3504,13$; teste $F($ Total $)=5119,91$. Análise de variância com valores transformados $(\sqrt{ } x)$.

$\left({ }^{2}\right)$ Letras iguais na coluna não diferem estatisticamente pelo teste de Tukey a $5 \%$.

Tabela 5. Composição mineral e análise química $\left(\mathrm{mg} \cdot \mathrm{L}^{-1}\right)$ dos meios nutritivos empregados no crescimento de plântulas de Miltonia spectabilis (Orchidaceae), após um ano de cultivo in vitro, em quatro repicagens sucessivas de três meses cada uma. $(n=5)$

\begin{tabular}{|c|c|c|c|c|c|c|c|c|}
\hline \multirow{2}{*}{ Análises } & \multirow{2}{*}{$10: 10: 10$} & \multirow{2}{*}{$10: 30: 20$} & \multicolumn{3}{|c|}{ Polpa } & \multirow{2}{*}{ Knudson } & \multirow{2}{*}{$\mathrm{V}$ e W } & \multirow{2}{*}{ MS } \\
\hline & & & Maçã & Tomate & Banana & & & \\
\hline $\mathrm{P}$ & 4,0 & 12,0 & $<0,1^{*}$ & 3,0 & $<0,1$ & $<0,1$ & 3,0 & 4,0 \\
\hline K & 10,0 & 14,0 & 4,0 & 8,0 & 11,0 & 32,0 & 27,0 & 6,0 \\
\hline $\mathrm{Ca}$ & 4,0 & 4,0 & 2,0 & 3,0 & 3,0 & 6,0 & 4,0 & 7,0 \\
\hline $\mathrm{Mg}$ & 0,5 & 0,5 & 0,5 & 1,0 & 0,5 & 1,0 & 1,0 & 2,0 \\
\hline$S$ & 4,0 & 3,0 & 3,0 & 8,0 & 3,0 & 9,0 & 12,0 & 14,0 \\
\hline $\mathrm{Fe}$ & 0,2 & 0,1 & $<0,1$ & 0,6 & 0,3 & 0,5 & 0,3 & 0,4 \\
\hline $\mathrm{Mn}$ & $<0,1$ & $<0,1$ & $<0,1$ & $<0,1$ & $<0,1$ & $<0,1$ & 1,0 & 0,1 \\
\hline $\mathrm{Zn}$ & 0,2 & 0,2 & 0,1 & 0,2 & 0,2 & 0,3 & 0,2 & 0,2 \\
\hline $\mathrm{Na}$ & 2,0 & 2,0 & 3,0 & 3,0 & 2,0 & 4,0 & 4,0 & 2,0 \\
\hline $\mathrm{pH}$ & 4,5 & 4,7 & 6,1 & 6,6 & 5,7 & 4,3 & 4,9 & 4,4 \\
\hline $\mathrm{CE}$ & 67 & 142 & 37 & 274 & 60 & 295 & 210 & 140 \\
\hline
\end{tabular}

* Valores abaixo do limite de deteç̧ão. 
Considerando a matéria seca total por plântula, a análise dos resultados revela que os meios nutritivos 10:30:20 e com polpa de banana proporcionaram o maior acúmulo e o meio MS, o menor. Em ordem decrescente de acúmulo de matéria seca total estão os meios 10:30:20 e polpa de banana, seguidos por 10:10:10 $(91,6 \%)$, polpa de tomate $(58,8 \%)$ e KnUdSOn $(58,3 \%)$, VAcin e Went $(18,7 \%)$, polpa de maçã $(13,2 \%)$ e MS $(4,1 \%)$.

Os valores obtidos para a relação PA/ raízes mostram, nas plântulas de $M$. spectabilis cultivadas nos meios nutritivos com polpa de banana e KNUDSON, acúmulos iguais de matéria seca na parte aérea e nas raízes, e nos meios nutritivos 10:10:10, 10:30:20 e polpa de maçã ocorreram, proporcionalmente, maiores acúmulos nas raízes e menores na parte aérea. $\mathrm{O}$ oposto foi observado nos meios com polpa de tomate, Vacin e Went e MS, nos quais ocorreram acúmulos relativos maiores na parte aérea, principalmente das plântulas cultivadas em meio com polpa de tomate.

\section{Laelia tenebrosa}

Os valores obtidos para o acúmulo de matéria seca e relação PA/raízes são mostrados na tabela 6 . Os valores de análise química, bem como a composição mineral são apresentados na tabela 7 . Nas plântulas cultivadas em meio nutritivo com 10:10:10 ocorreu o maior acúmulo na parte aérea, enquanto as plântulas cultivadas em meio com 10:30:20, polpa de tomate ou MS foram as que menos matéria seca acumularam na parte aérea. É interessante notar que o segundo maior acúmulo na parte aérea, ou seja, plântulas cultivadas em meio com polpa de banana, correspondem a $53,6 \%$ do primeiro. Em relação ao observado nas raízes, plântulas cultivadas em meio com polpa de banana obtiveram maiores acúmulos; já as plântulas cultivadas em meio com 10:30:20 ou polpa de tomate foram as que menos cresceram. Diferentemente do que ocorreu na parte aérea, plântulas cultivadas em meio com 10:10:10 tiveram o segundo maior acúmulo nas raízes, correspondendo a 13,8\% em relação ao primeiro.

Considerando a matéria seca total, as plântulas cultivadas em meio com polpa de banana incorporaram maior quantidade de matéria seca, sendo seguidas pelas plântulas cultivadas em meio com 10:10:10, que acumularam $38,7 \%$ em relação às primeiras. Nos demais meios nutritivos, o acúmulo verificado foi reduzido, representando nos meios 10:30:20, polpa de tomate e MS, 2,75\% da matéria seca acumulada em plântulas no meio com polpa de banana.

Os valores da relação PA/raízes mostram que nos meios nutritivos com polpa de maçã, VACIN e WENT, principalmente, com polpa de banana, o particionamento da matéria seca na plântula favoreceu o maior acúmulo de matéria seca nas raízes, enquanto os meios KNUDSON, polpa de tomate, 10:30:20 e 10:10:10 proporcionaram maior acúmulo na parte aérea. As plântulas cultivadas em meio MS tiveram um dos menores acúmulos na matéria seca total, porém, com igual distribuição entre parte aérea e raízes.

Tabela 6. Acumulo de matéria seca e relação alométrica após quatro cultivos sucessivos de três meses, em plântulas de um ano de Laelia tenebrosa (Orchidaceae), quando crescidas em diferentes meios nutritivos, in vitro. Os valores de matéria seca são dados para a parte aérea (P.A.), raízes e total $(n=5)$

\begin{tabular}{|c|c|c|c|c|}
\hline \multirow[b]{2}{*}{ Tratamentos } & \multicolumn{3}{|c|}{ Matéria Seca $\left({ }^{1}\right)$} & \multirow[b]{2}{*}{ P.A./Raízes } \\
\hline & P.A. $\left({ }^{2}\right)$ & Raízes $\left({ }^{2}\right)$ & Total $\left({ }^{2}\right)$ & \\
\hline & 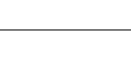 & g / plântu & 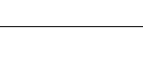 & \\
\hline 10:10:10 (N:P:K) & $26,70 \mathrm{a}$ & $11,69 \mathrm{~b}$ & $38,39 \mathrm{~b}$ & 2,28 \\
\hline 10:30:20 (N:P:K) & $1,75 \mathrm{e}$ & $1,05 \mathrm{f}$ & $2,80 \mathrm{f}$ & 1,67 \\
\hline Polpa de maçã & $3,87 \mathrm{~d}$ & $4,50 \mathrm{~d}$ & $8,37 \mathrm{e}$ & 0,86 \\
\hline Polpa de tomate & $1,50 \mathrm{e}$ & $1,00 \mathrm{f}$ & $2,50 \mathrm{f}$ & 1,50 \\
\hline Polpa de banana & $14,32 \mathrm{~b}$ & $84,93 \mathrm{a}$ & $99,25 \mathrm{a}$ & 0,17 \\
\hline Knudson & $12,17 \mathrm{C}$ & $8,29 \mathrm{c}$ & 20,46 c & 1,47 \\
\hline $\mathrm{V} \& \mathrm{~W}$ & $4,34 \mathrm{~d}$ & $8,18 \mathrm{c}$ & $12,65 \mathrm{~d}$ & 0,53 \\
\hline MS & $1,45 \mathrm{e}$ & $1,43 \mathrm{e}$ & $2,88 \mathrm{f}$ & 1,01 \\
\hline
\end{tabular}

$\left({ }^{1}\right)$ Teste $\mathrm{F}$ (P.A.) $=1185,18$; teste $\mathrm{F}$ (Raízes) $=5900,11$; teste $\mathrm{F}($ Total $)=4778,57$. Análise de variância com valores transformados $(\sqrt{ } \mathrm{x})$.

$\left({ }^{2}\right)$ Letras iguais na coluna não diferem estatisticamente pelo teste de Tukey a $5 \%$. 
Tabela 7. Composição mineral e análise química $\left(\mathrm{mg} \cdot \mathrm{L}^{-1}\right)$ dos meios nutritivos empregados no crescimento de plântulas de Laelia tenebrosa (Orchidaceae), após um ano de cultivo in vitro, em quatro repicagens sucessivas de três meses cada uma. $(\mathrm{n}=5)$

\begin{tabular}{|c|c|c|c|c|c|c|c|c|}
\hline \multirow{2}{*}{ Análises } & \multirow{2}{*}{$10: 10: 10$} & \multirow{2}{*}{$10: 30: 20$} & \multicolumn{3}{|c|}{ Polpa } & \multirow{2}{*}{ Knudson } & \multirow{2}{*}{ V e W } & \multirow{2}{*}{ MS } \\
\hline & & & Maçã & Tomate & Banana & & & \\
\hline $\mathrm{P}$ & 6,0 & 10,0 & $<0,1^{*}$ & 6,0 & $<0,1$ & 3,0 & 1,0 & $<0,1$ \\
\hline K & 7,0 & 12,0 & 5,0 & 12,0 & 9,0 & 4,0 & 19,0 & 18,0 \\
\hline $\mathrm{Ca}$ & 3,0 & 3,0 & 3,0 & 3,0 & 2,0 & 8,0 & 3,0 & 3,0 \\
\hline $\mathrm{Mg}$ & 0,5 & 0,5 & 0,5 & 1,5 & 0,5 & 1,0 & 1,0 & 1,0 \\
\hline$S$ & 3,0 & 1,0 & 2,0 & 6,0 & 2,0 & 10,0 & 11,0 & 5,0 \\
\hline $\mathrm{Fe}$ & 0,3 & 0,2 & $<0,1$ & 0,7 & 0,4 & 0,5 & 0,5 & 0,7 \\
\hline $\mathrm{Mn}$ & $<0,1$ & $<0,1$ & $<0,1$ & $<0,1$ & $<0,1$ & $<0,1$ & 0,6 & $<0,1$ \\
\hline $\mathrm{Zn}$ & 0,2 & 0,1 & 0,2 & 0,3 & 0,1 & 0,2 & 0,2 & 0,3 \\
\hline $\mathrm{Na}$ & 2,0 & 2,0 & 3,0 & 3,0 & 1,0 & 2,0 & 3,0 & 3,0 \\
\hline $\mathrm{pH}$ & 4,3 & 5,0 & 6,0 & 6,4 & 554,8 & 4,6 & 4,9 & 4,6 \\
\hline $\mathrm{CE}$ & 86 & 138 & 46 & 405 & 55 & 134 & 158 & 168 \\
\hline
\end{tabular}

* Valores abaixo do limite de detecção.

Deve ser lembrado que a família Orchidaceae é, provavelmente, a maior família botânica entre as Angiospermas, englobando espécies vegetais distintas e as três orquídeas estudadas possuem características fenotípicas singulares e ocorrem em diferentes hábitats. Em decorrência, existe uma infinidade de meios nutritivos que são empregados e recomendados para a micropropagação de diferentes grupos de orquídeas (VillaLobos et al., 1991), sendo enfatizada a adição de misturas complexas (CALDAs et al., 1998), principalmente polpa de alguns frutos.

De acordo com WATT e MERRILL (1963), análises químicas revelam a presença de cálcio, fósforo, ferro, potássio, vitamina $\mathrm{A}$, tiamina, riboflavina, niacina e ácido ascórbico na polpa de banana, maçã e tomate, porém, em diferentes concentrações; em geral, a polpa de maçã não tem vitamina $A$, a polpa de banana possui altos teores de potássio e fósforo e a polpa de tomate exibe alta concentração de sódio, vitamina A e de potássio. Nesse trabalho, os meios continham exclusivamente polpa de banana, polpa de maçã ou polpa de tomate, mais a sacarose, sem a complementação com sais minerais, vitaminas ou quaisquer outros tipos de substâncias, como ocorreu com os meios KNUDSON, VACIN e WENT e MS. Igualmente, nos meios com 10:10:10 ou 10:30:20 havia somente sacarose.

De acordo com ARditTi (1968 e 1992), CALDAS et al. (1998) e VAlmayor e Price (1970), entre outros, experimentos desenvolvidos in vitro têm demonstrado que a polpa da banana é o melhor suplemento para a diferenciação de órgãos e promotor do crescimento de raízes e folhas; além disso, em algumas espécies de orquídeas epífitas, o crescimento das raízes foi superior ao crescimento da parte aérea, como verificado neste trabalho para a espécie $L$. tenebrosa. Também, é possível que os meios nutritivos 10:10:10 e 10:30:20 tenham proporcionado maior crescimento devido às baixas concentrações de sais minerais, reforçando dados da literatura (ARDitTI, 1992; KNUDSON, 1946), que demonstram a baixa demanda por nutrientes minerais que as orquídeas exibem.

Por sua vez, o meio com polpa de tomate favoreceu o acúmulo de matéria seca total em plântulas de L. longipes e M. spectabilis, principalmente na parte aérea, mas prejudicou o crescimento de plântulas de L. tenebrosa. Porém, de acordo com ArditTI (1982 e 1992), Hoshi et al. (1994) e Ramos (1969), o uso da polpa de tomate em adição com vitaminas e sais minerais estimula a germinação e o crescimento in vitro de espécies de orquídeas epífitas e terrestres. Da mesma maneira, a inclusão da polpa de maçã no meio de cultura melhorou a germinação e o crescimento de plântulas micropropagadas. Em experimentos realizados por ARDitTI (1992); BUtCHER e MARLOW (1989), notou-se incremento de matéria seca em plântulas de orquídeas epífitas dos gêneros Dendrobium, Phalaenopsis e Vanda, quando cultivadas em meio nutritivo suplementado com a polpa de maçã. No presente trabalho, por razões que necessitam estudos mais detalhados, o meio nutritivo contendo polpa de maçã prejudicou o crescimento das plântulas, proporcionando um dos menores acúmulos de matéria seca, favorecendo mais o crescimento das raízes que da parte aérea. 
Os meios Knudson e Vacin e Went são mundialmente conhecidos, sendo empregados para a micropropagação de orquídeas epífitas e terrestres. Proporcionam crescimento vigoroso às plântulas da maioria das espécies de orquídeas e são compostos por macro e micronutrientes minerais em baixas concentrações, principalmente quando comparadas às concentrações do meio Murashige e SKoOg (1962). Porém, os meios nutritivos com polpa de banana, 10:10:10 e 10:30:20 foram os que proporcionaram maior crescimento, sendo as plântulas cultivadas com polpa de banana aquelas com maior acúmulo de matéria seca total, para as três espécies estudadas. Esses dados reforçam a hipótese de que espécies de orquídeas cultivadas in vitro necessitam da baixa concentração dos sais minerais no meio de cultura, uma vez que vivem em ambientes com baixa disponibilidade de nutrientes.

Para os tratamentos com polpa de banana, 10:10:10 e 10:30:20, é provável que nessas condições a fonte de açúcar tenha efetivamente contribuído para o incremento de matéria seca das plântulas cultivadas nesses meios, já que foram acrescidos $2 \%$ de sacarose, a principal fonte de esqueletos de carbono. Como na prática a polpa de fruto está associada aos meios KNUDSON e VACIN e WENT, seria correto afirmar que o crescimento alcançado pelas plântulas cultivadas nos meios contendo somente a polpa de fruto tenha sido menor, principalmente tomate ou maçã, devido à interação sinérgica ou à ação complementar, que fornecem condições mais adequadas para o rápido incremento da matéria seca.

\section{REFERÊNCIAS}

ARDITTI, J. Germination and growth of orchids on banana fruit tissue and some of its extracts. American Orchid Society Bulletin, West Palm Beach, v. 37, p. 112-116, 1968.

ARDITTI, J. Orchid seed germination and seedling culture : A manual. In: Arditti, J. (Ed.), Orchid biology: Reviews and perspectives. Ithaca: Comstock Publishing Associates, 1982, v. 2, p. 244-370.

CALDAS, L.S.; HARIDASAN, P. ; FERREIRA, M.E. Meios nutritivos. In: Torres, A.C.; Caldas L.S.; Buso J.A. (Ed.). Cultura de tecidos e transformação genética de plantas. Brasília: EMBRAPA-SPI, 1998, v. 1, p. 87-132.

GAMBORG, O. Plant cell cultures: nutrition and media. In: Vasil I.K. (Ed.). Cell culture and somatic cell genetics of plants, New York, Academic Press, 1984. v. 1, p. 18-26.

HOSHI, Y.; KONDO, K.; HAMATAMI, S. In vitro germination of four Asiatic taxa of Cypripedium and notes on the nodal micropropagation of American Cypripedium montanum. Lindleyana, West Palm Beach, v.9, p. 93-97, 1994.
KNUDSON, L. A new nutrient solution for germination of orchid seed. American Orchid Society Bulletin, West Palm Beach, v. 15, p. 214-217, 1946.

MURASHIGE, T.; SKOOG, F. A revised medium for rapid growth and bio assays with tobacco tissue cultures. Physiologia Plantarum, Copenhagen, v. 15, p. 473-497, 1962.

RAMOS, M.S.S. O uso do tomate nos meios de cultura. In: A orquídea e a sua reprodução pela semente. São Paulo: Saraiva, 1969. p. 47-52.

REINNERT, R.A.; MOHR, H.C. Propagation of Cattleya by tissue culture of lateral bud meristems. Journal of the American Society for Horticultural Science, Alexandria, v. 91, p. 664-671, 1967.

VALMAYOR, H.L.; PRICE, G.R. Banana fruit pulp: a good medium for growing orchids. Agriculture at Los Banos, Los Banos, v. 9 n4, p. 142-152, 1970.

VACIN, E.F.; WENT, F.W. Some pH changes in nutrient solutions. Botanical Gazette, Cambridge, v. 110, p. 605-613, 1949.

VILLALOBOS, U.M.; FERREIRA, P.; MORA, A. The use of biotechnology in the conservation of tropical germoplasm. Biotechnology Advances, Cambridge, v. 9, p. 197-215, 1991.

WATT, B.K.; MERRILL, A.L. Composition of foods. Washington, DC: USDA, 1963. 129p. (Agriculture Handbook n.8.)

WHITE, P.R. Nutritional requirements of isolated plant tissues and organs. Annual Review of Plant Physiology, Cambridge , v. 2, p. 231-244, 1951.

WITHNER, C.L. The orchids: a scientific study. Nova Iorque: Wiley-Interscience, John Wiley \& Sons, 1974. 451p. 